\title{
Design of Microstrip Line-Coupled Isosceles-Triangular Loop Resonator Antenna
}

\author{
(Rekabentuk Antena Pengayun Gelung Segi Tiga Kaki Sama Terganding Garis Jalur Mikro)
}

Seyi Stephen Olokede*, Mohd Fadzil Ain, Mohammed Ariff Othman, Ubaid Ullah \& Zainal Araffin Ahmad

\section{ABSTRACT}

In this paper, an experimental study on a microstrip line proximity coupled triangular microstrip loop resonator antenna is presented. The antenna is fed by a $50 \Omega$ microstrip feed line arrangement at the frequency of $5.8 \mathrm{GHz}$. The antenna element is placed at $\lambda_{g} / 4$ from the stub, and $\lambda_{g} / 2$ away from the feed based on the voltage allocation on an open ended transmission line where $\lambda_{g}$ is the guided wavelength. The antenna element was rotated 90 degree clockwise about the $z$-axis in parallel with the microstrip feed. This was done in order to 1) ensure a good proximity coupling, and 2) to indicate that the amount of coupling from the microstrip line to the resonator can be controlled to a certain degree by adjusting the spacing. A similar design was done without rotating the resonator, and the result is reported. It was observed that the measured $\left|\mathrm{S}_{11}\right|$ of the rotated element is superior to the un-rotated by $43.75 \%$, and $40.43 \%$ for the simulated. In all, experimental results agreed significantly with simulated results.

Keywords: Antenna; isosceles triangle; loop; microstrip; triangular antenna

\section{ABSTRAK}

Dalam kertas ini, satu kajian eksperimen ke atas antena pengayun gelung segi tiga kaki sama terganding garis talian jalur mikro dibentangkan. Antena tersebut diberi suapan oleh $50 \Omega$ susunan talian suapan jalur mikro pada frekuensi $5.8 \mathrm{GHz}$. Elemen antena diletakkan di kedudukan $\lambda_{g} / 4$ daripada puntung, dan $\lambda_{g} / 2$ dari suapan berdasarkan peruntukan voltan pada talian penghantaran terbuka di mana $\lambda_{g}$ adalah panjang gelombang terpandu. Elemen antena telah diputar 90 darjah mengikut arah jam pada paksi $-z$ selari dengan jalur mikro suapan. Perkara ini dilakukan untuk 1) memastikan gandingan berdekatan yang baik, dan 2) untuk menunjukkan bahawa jumlah gandingan dari garis jalur mikro ke pengayun boleh dikawal pada tahap tertentu dengan melaraskan jaraknya. Satu reka bentuk yang sama telah dilakukan tanpa memutarkan pengayun, dan hasilnya telah dilaporkan. Diperhatikan $\left|\mathrm{S}_{11}\right|$ yang diukur untuk elemen putar adalah lebih baik daripada elemen yang tidak diputar sebanyak 43.75\%, dan 40.43\% bagi keputusan simulasi. Keseluruhannya, keputusan eksperimen selari dengan ketara dengan keputusan simulasi.

Kata kunci: Antena; segi tiga sama kaki; gelung; jalur mikro; antena segi tiga

\section{INTRODUCTION}

Applications requiring physically small size are currently Applications requiring physically small size are currently ubiquitous. Antennas are now required to be physically and in most cases also electrically small (Wansch 2002) because of the reduced size of the wireless devices. In recent times, conventional microstrip patch antennas have been unsuitable because of the size requirement, particularly for mobile communication applications (Vendelin et al. 2005). The increasing needs for small antennas are due to the pressing demands for low manufacturing cost, portability, strait space requirement, and light weight for portability and easy mobility. As a result of compactness, the small antennas are feasible to be integrated with monolithic integrated circuit or MIC.
MIMO technology has attracted attention in wireless communications in the recent times, because of its significant increase in data throughput capability and link range efficiency without additional bandwidth or increased transmit power. Though coding and signal processing are key elements to successful implementing a MIMO system, the propagation channel and antenna design represent major parameters that ultimately impact the system performance. To create an efficient MIMO antenna system on a wireless handy device, only small space is allocated, and therefore, small and compact antenna is preferable.

The efficiency of the antenna should be high enough to ensure long battery life as most of the terminals are battery-driven (Waldschmidt et al. 2005). Radar system 
need to be improved to support next generation Air Defense System which include transportability, remote operation in strait, intense, dense terrain, high mobility, high degree identification precision and increased sensitivity to detect smaller targets at longer ranges (Harlan et al. 2006). Consequently, small and compact antenna is desirable to fulfill these requirements. On the average, the specific advantages of using small size antenna element, is not only to contribute to the reduction on antenna weight and but also, lead to the lighter rotators for the mechanical scanning.

However, existing study with the view to ameliorate the enormous challenges confronting design of small antennas has been insufficient. Often times, the compactness of these antennas makes it difficult to be efficiently matched, as the antennas themselves are most times considerably smaller than the feed. Moreover, the reduction in antenna size present performance penalties in terms of bandwidth and efficiency the compactness of these antennas makes it difficult to be efficiently matched, as the antennas themselves are most times considerably smaller than the feed. To this end, a novel $5.8 \mathrm{GHz}$ triangular microstrip loop resonator antenna has been proposed. Ogasawara and Noguchi (1974) introduced the triangular resonator. Thereafter, Hong and Li (2004) implemented microstrip filters using triangular patch. Subsequently, Helszajn and James (1978) analyzed the field patterns of a planar microstrip triangular patch. Ever since then, microstrip triangular resonators were famous due to their compact capabilities, and also possibility of dual frequencies as a result of dual mode potential (Lu,. 1999). In (Helszajn \& James, 1978; Wang et al., 2003; Chen \& Xue 2005; Nasimuddin et al., 2005), triangular patch resonator was investigated and reported. Shortly thereafter, microstrip triangular loop resonator was reported in (Lugo \& Papapolymerou, 2005, Tautain et al. 2001; Zhao et al. 2007) and since then various application using triangular patch is reported in (Saputra et al.; Das et al. 2013; Deshmukh et al. 2013; Dam et al 2013; Malek et al. 2013; Zulkifli et al. 2013; Arulalaan \& Nithyanandan 2013).

In all of these, the existing work on microstrip triangular loop resonator were concentrated either on filter designs, or on circularly polarized (CP) antenna. Therefore, four objectives are set in order to effectively investigate the proposed antenna. First is to examine the characteristics of the proposed antenna with the view to determining its suitability, and consequently, its adaptability as an antenna candidate. The second is to determine if the proposed resonator will present a significant antenna size reduction capability both in terms of footprint and real estate. Third is to formulate the theoretical framework for such an alternative antenna structure cum the feed mechanism. Fourth is to compare the proposed antenna with another though with the same configuration but with the resonator rotated $90^{\circ}$ about the $\mathrm{z}$-axis. The proposed antenna element is an isosceles triangular microstrip loop resonator antenna, which is half of a typical conventional rectangular microstrip patch antenna.

\section{THEORETICAL FRAMEWORK}

THE ANTENNA TOPOLOGY

Figure 1(a) shows a microstrip square loop resonator divided into two equal parts along its diagonal axis. The resultant triangles form two equal isosceles triangles with two equal sides of length $l$, and the base length of $a$. Figure 1(b) depicts one of the triangles, which is the focus of this work. Though, cutting a part of the structure can change the field distribution and inspire the degenerate modes. Nonetheless, the cross couplings between the degenerate modes can not only generate attenuation poles but also cause the resonant frequency of higher harmonic wave to shift. Hence, it can be used for the miniaturization of the antenna design. Based on the analysis of resonant modes theory and slow effect, it is estimated that the triangular patch function is equal to $50 \%$ of the rectangular microstrip patch, not to talk of the triangular microstrip loop (Matsuo et al. 2001).

Similarly, the proposed antenna element is a half cut from the square microstrip loop resonator, thus saving at least $50 \%$ of the antenna footprint and hence, the real estate. Essentially, this technique will reduce cost drastically due to low mass especially as compared to the triangular microstrip patch (Matsuo et al., 2001). Detailed analysis of different resonator positions with respect to the sizes of perturbation has been reported in [14]. Rigorous analysis of the radiation pattern, degenerate modes and coupling factor was also documented. It is worthy of note that though the triangular microstrip patch function is $50 \%$ of the entire rectangular microstrip patch antenna structure. In the same vein, the triangular loop function is also $50 \%$ of the entire rectangular microstrip loop resonator.

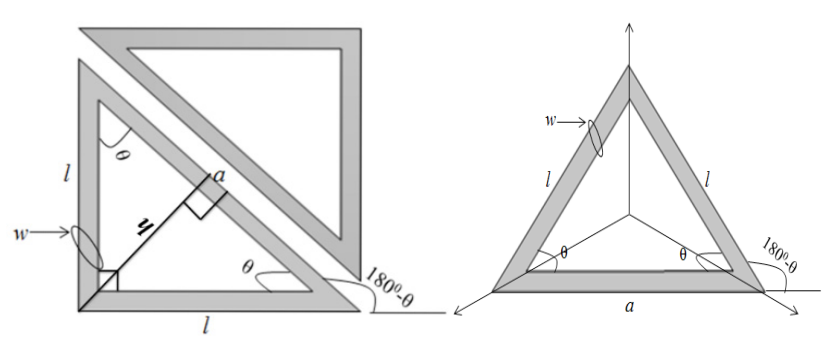

FIGURE 1. Single element microstrip triangular loop resonator.

Therefore, comparing the triangular loop to the triangular patch indicates that the triangular patch function exhibits heavy mass than the triangular microstrip loop resonator seeing it's a loop. Thus, the entire surface area of the proposed antenna element is the differential area between the outer and inner isosceles triangle patches. Consequently, the proposed resonator becomes significantly small and lighter in the same proportion and hence, a correspondence reduction in cost of production.

Equations to determine the resonant frequency of the proposed resonator is stated in (1), where $1_{g}$ is the girded wavelength as well as the perimeter of the proposed 
resonator, $c$ is the speed of light in free space, $\mathrm{e}_{\text {eff }}$ is the effective dielectric constant of the substrate, $a$ is the base length and $l$ is the side lengths of the triangle. According to equation (1), while a resonant frequency is fixed at 5.8 $\mathrm{GHz}$,

$$
f=\frac{c}{\lambda_{g} \sqrt{\varepsilon_{e f f}}}
$$

$\lambda_{g}$ decreased considerably to further realize size reduction as $\varepsilon_{\text {eff }}$ increased, knowing full well that the loop resonator is a wavelength long microstrip line. Similarly, for a fixed $\varepsilon_{e f f}$, the resonant frequency $f$ also decreases as the perimeter increases, thus achieving a moderate degree of design flexibility and freedom. Therefore, the proposed antennas were fed by a microstrip feed line. At the rotated position, the baseline of the resonator run parallel to the microstrip feed line with a lateral coupling space $s=0.3 \mathrm{~mm}$. A magnetic coupling was established by the reason of the configurations. Rigorous equations, coupling types and adaptable equivalent circuit were reported in (Hong \& Lancaster 1996). Observation using CST microwave studio and demonstrated by (Hong \& Lancaster 1996), indicates that the magnetic coupling coefficient $\mathrm{K}_{\mathrm{M}}$ (which is a ratio of coupled magnetic energy to the stored energy of the uncoupled resonator) reduces as the spacing $s$ increases.

\section{THE COUPLING MECHANISM OF THE FEED}

A common method of coupling in microwave circuits is by proximity coupling to the resonator. Figure 2 shows this feeding technique as applied to the proposed antenna where $\mathrm{s}$ is the spacing between the feed and the proposed resonator. The amount of coupling from the microstrip line to the resonator can be control by adjusting the spacing $s$.

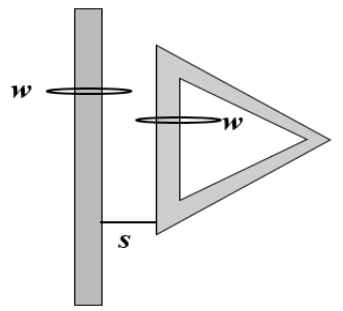

FIGURE 2. The coupling Mechanism.

This action inadvertently present a capacitive entries to the antenna performance. The resulting geometry arrangement is analogous to a capacitor like structure with the feed line and the baseline of the resonator serving as the parallel plates with a dielectric distance $s$, where the spacing acts as the dielectric permittivity (c). A more dominant parameter affecting the degree of coupling is the dielectric constant of the dielectric distance. Essentially, the arrangement forms a planar capacitor width of capacitance (He et al., 2000)

$$
C=\varepsilon \varepsilon_{0} \frac{w^{2}}{4 s}
$$

where $w$ is the width of the feed line and the baseline of the resonator which was calculated to be $1.89 \mathrm{~mm}$ using equation (6), $\varepsilon_{0}$ is the permittivity of free space, and $\varepsilon$ is the dielectric constant of the medium filling the gap $s$.

\section{RADIATION MECHANISM OF THE PROPOSED ANTENNA}

The proposed antennas were fed by a microstrip feed line and excited with a coaxial feed probe as shown in Figure 3. The transmission line feed produces charge distribution at both sides of the resonator, as well as the ground plane. As a result of the feed effect, this creates positive and negative field distribution similar to what was obtainable in a microstrip line-fed rectangular microstrip patch antenna. The repulsive force between these positive charges creates a charge density around the edges of the triangle. Therefore, the fringing fields caused by these charges are responsible for radiation in the surrounding. The radiation characteristics and field distribution pattern has been analyzed by Helszajn \& James 1978). The TM fields, the radiation quality factor, and performance profile of triangular resonator were also reported.

\section{ANTENNA GEOMETRY}

The proposed single element antenna comprises of an isosceles triangular microstrip loop resonator photo edged on a grounded RT/Duroid RO4003C dielectric substrate with dielectric permittivity of 3.38 and a thickness of $0.813 \mathrm{~mm}$. The isosceles triangle that forms the triangular microstrip loop resonator was first configured in such a way that the base line was positioned on a straight line with zero degree with the $x$-axis as shown in Figure 3 . The base line was $12 \mathrm{~mm}$, whereas, the side lengths are $8 \mathrm{~mm}$ each with a height of about $5 \mathrm{~mm}$.

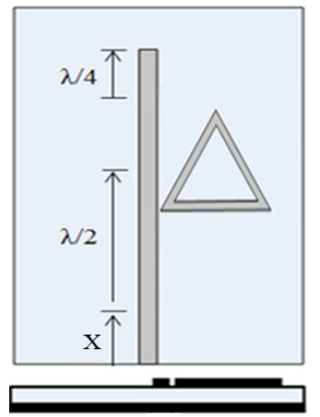

FIGURE 3. Geometry of the un-rotated single element proposed antenna 
The stub length was $\lambda_{\mathrm{g}} / 4$, whereas the other length of the transmission line is $\lambda_{\mathrm{g}}^{\mathrm{g}} / 2$ where $\lambda_{\mathrm{g}}$ is equal to $28 \mathrm{~mm}$ at a centre frequency of $5.8 \mathrm{GHz}$. It has been estimated that the impedance band width of an antenna improves significantly when the radiating element is positioned at $\lambda_{\mathrm{g}} / 4$ open stub seeing that current and voltage are at quadrature, and that maximum radiation will exist at such location as demonstrated much more below. It was observed that the proximity coupling between the resonator and the feed was week. The estate area of the proposed is $11 \times 8 \mathrm{sq}$. $\mathrm{mm}$. The proposed resonator was rotated 90 degree in a clockwise direction about the Z-axis as shown in Figure 4. This was done in such a way that the base length of the triangular loop runs parallel to the microstrip feed line, and thus provides sufficient interface for proper proximity coupling.

At the rotated position, the baseline of the resonator run parallel to the microstrip feed line. A magnetic coupling was established by the reason of the configurations. Again, the lateral spacing between the feed and the resonator was set to $0.3 \mathrm{~mm}$. Varying the lateral spacing using CST microwave studio demonstrated that the optimum coupling distance was somewhere in the neighbourhood of $0.1 \mathrm{~mm}$ from the feed, and tends to nose dive as it moves away.

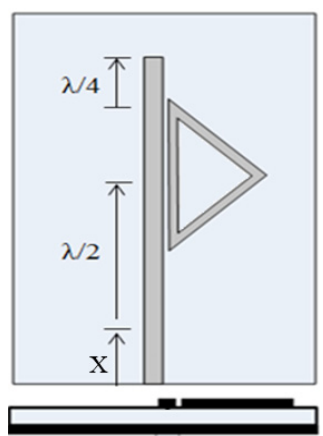

(a)

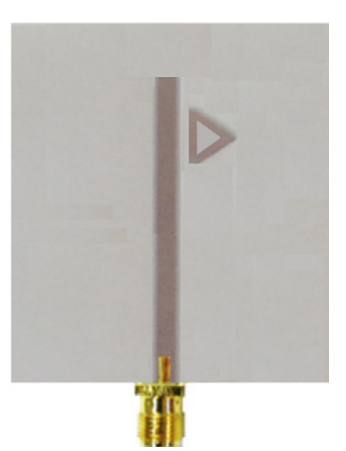

(b)
FIGURE 4. Geometry of the single element proposed antenna.

Though it is expedient to design at this optimum coupling distance, it is however not realizable due to etching limitations. The single element triangular microstrip loop resonator antenna was fed by a microstrip feed line of width $1.89 \mathrm{~mm}$. The proposed design is as shown in Figure 4(a) whereas, its fabricated prototype is as shown in Figure 4(b).

The feed arrangement employs the voltage allocation over the length of the microstrip line where the load end of the line is shorted (i.e. terminated) in a stub as shown in Figure 5. The same impedance and voltage condition is periodic every half-wavelength down further the line from the load completion toward the generator (which in this case is the coaxial feed excitation). Voltage minima are called nodes, whereas voltage maxima are called antinodes (Bakshi \& Bakshi 2009; Carr 2001).
Since the antinodes is going to repeat itself every half wavelength along the transmission line, the resonator was positioned at the half wavelength location in order to get maximum power radiation. The distance between the open circuited end of the feed line and the resonator was a quarter wavelength. $\mathrm{X}$ was the distance between the input signal point and the microstrip end, and must be less than half wavelength in order to prevent more antinodes along the microstrip line.

The resonance frequency occurs when $\lambda_{\mathrm{g}}$ is equal to the perimeter of the isosceles triangle, and the equation to determine the resonant frequency of the microstrip triangular loop resonator antenna was given in equation (1). The distance of the stub was meticulously selected to match the input impedance of the antenna.

When microstrip-fed coaxially excited patch radiators are designed, the coaxial feed probe can be placed at any location, and the impedance match will depend on its location. The stub lengthening $\mathrm{S}$ is mostly chosen to be defined as stated in equations (3) through to (6)

$$
S=\frac{\lambda_{g}}{4}
$$

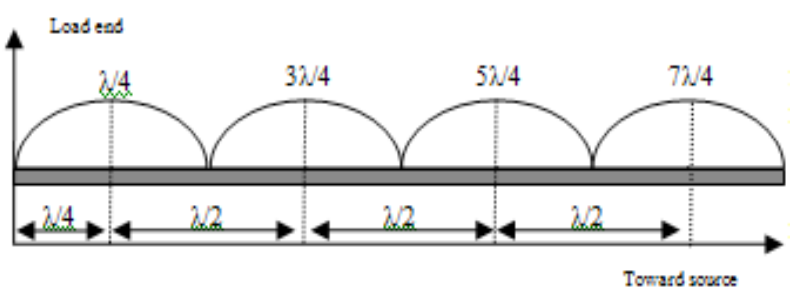

FIGURE 5. Voltage allocation over a microstrip line.

The advantage of this technique is that an improved impedance match will ideally increase the bandwidth, the return loss and improve performance by reducing the excitation of unwanted modes of radiation. Equations to find the guided wavelength are stated as in Equations (4) through to (6).

$$
\begin{gathered}
\lambda_{g}=\frac{\lambda_{0}}{\sqrt{\varepsilon_{\text {eff }}}} \\
\varepsilon_{\text {eff }}=\frac{\left(\varepsilon_{r}+1\right)}{2}+\frac{\left(\varepsilon_{r}-1\right)}{2}\left[1+10 \frac{h}{w}\right]^{-0.555} \\
\left.\frac{w}{h}=\frac{2}{\pi}\left[\left(\frac{59.95 \pi^{2}}{Z_{0} \sqrt{\varepsilon_{r}}}\right)-1\right)-\ln \left(2\left(\frac{59.95 \pi^{2}}{Z_{0} \sqrt{\varepsilon_{r}}}\right)-1\right)+\right] \\
\left.\frac{\varepsilon_{r}-1}{\pi \varepsilon_{r}}\left[\ln \left(\frac{59.95 \pi^{2}}{Z_{0} \sqrt{\varepsilon_{r}}}-1\right)\right]+0.293-\frac{0.517}{\varepsilon_{r}}\right]
\end{gathered}
$$


where

$\mathrm{h}=$ Substrate thickness

$\varepsilon_{\mathrm{r}}=$ Relative permittivity of the substrate

$\mathrm{Z}_{0}=$ Characteristic impedance

$\mathrm{w}=$ Microstrip feed width

\section{RESULTS AND DISCUSSIONS}

Antenna measurements in free space were performed with an Agilent N5245A-PNA-X Network Analyzer providing up to $50 \mathrm{GHz}$. Figure 6 shows the simulated and measured reflection coefficient $|\mathrm{S} 11|$ on free space. The bandwidth of the proposed antenna ranges from 5.71 to $5.87(|\mathrm{~S} 11|<-10 \mathrm{~dB})$. Hence, the frequency coverage of the proposed design is sufficiently wide and relatively stable for the desired bandwidth. The simulated and measured return loss results of the proposed antenna are shown in Figure 6.

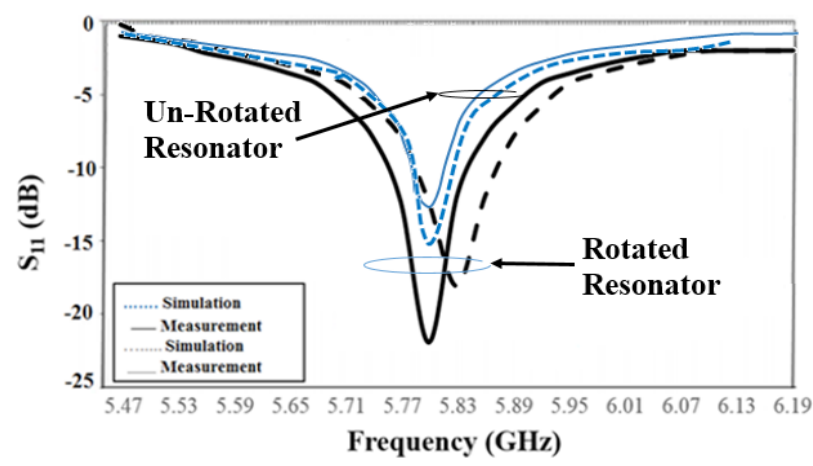

FIGURE 6. Simulated and measured return loss of the proposed antenna.

The simulated return loss with normal resonator was better than $10 \mathrm{~dB}$ and put at $30.8 \mathrm{~dB}$ with frequency pattern of 5.71-5.87 GHz, approximating $160 \mathrm{MHz}$ of bandwidth and input impedance of $49.12+\mathrm{j} 0.89 \Omega$ and measured value of $54.10-\mathrm{j} 1.06 \Omega$ as shown in Figure 7 .

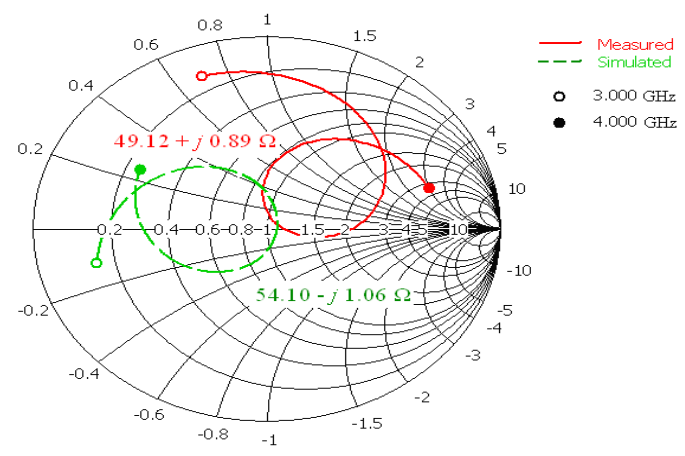

FIGURE 7. Simulated and measured Smith chart proposed antenna.

However, the measured return loss was put at $13 \mathrm{~dB}$ with a bandwidth pattern of 5.79-5.86. There is a significant low coupling due to weak proximity coupling. In reality,

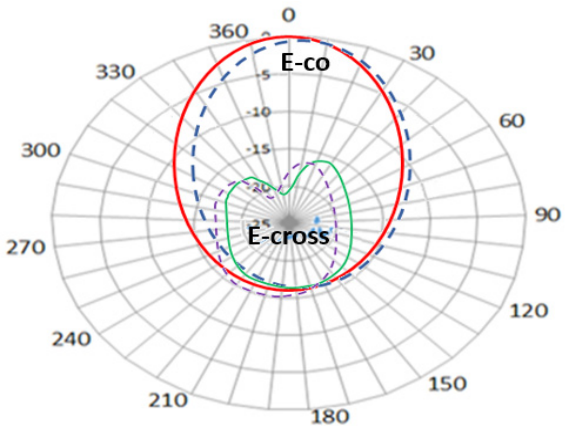

(a) $x z$-Plane

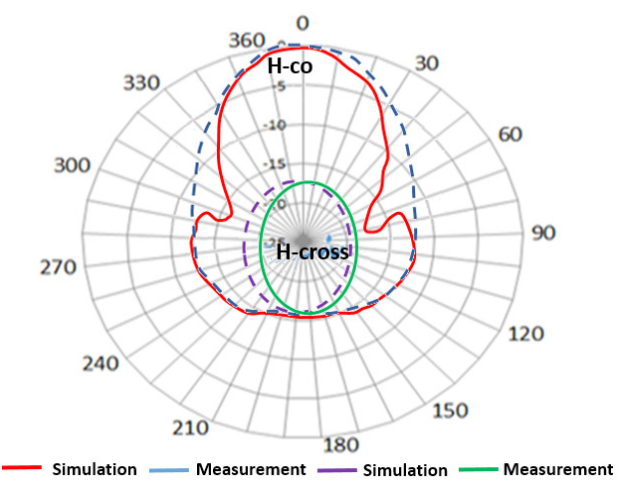

(b) $y z$-Plane

FIGURE 8. Simulated and measured radiation pattern

the nature and the extent of the fringe fields determine the characteristics and the strength of the coupling.

The coupling between the resonator and the microstrip feed line is predominantly proximity coupling, and essentially depends on the surface area interface between the feed and the resonator. Therefore, the resonator was rotated by $90^{\circ}$ such that the hemline was in parallel with the microstrip feed.

The rotated resonator return loss was better as shown in the same figure. The simulated return loss improved to $23 \mathrm{~dB}$ with a better frequency pattern of 5.70-5.88 GHz. Similar result was obtained for the measured frequency pattern but with a return loss of $21 \mathrm{~dB}$. More significantly, both measured and simulated return loss curves are in good agreement. The normalized radiation pattern results were as shown in Figure 7 in $x z$ - and $y z-$ planes respectively.

The main lobe was oriented in zero degree direction with a beamwidth of 66.6 degree. In $y z$-plane, the main magnitude was $5.6 \mathrm{~dB}$ with a direction of 30 degree and beamwidth of 73.90 degree. According to IEEE Standard Test Procedures for Antennas, ANSI/IEEE Std 149-1979, the most commonly employed method for antenna gain measurement is gain-transfer (gain-comparison) method. This technique utilizes a gain standard antenna to determine the absolute gains. The procedure requires two sets of measurements. In one set, using the test antenna as receiving antenna the received power $\left(P_{T}\right)$ was recorded. In the other set, the test antenna was replaced by the standard 
gain antenna and the received power $\left(P_{S}\right)$ was recorded. In both sets, the geometrical arrangement was maintained intact, and the input power was maintained the same.

This method is deployable both in the anechoic chamber as well as in open-space. Equation (7) below was used to calculate the gain of antenna under test:

$$
\left(G_{T}\right)_{d B}=\left(G_{S}\right)_{d B}+10 \log _{10}\left(\frac{P_{T}}{P_{S}}\right)
$$

where $G_{T}$ is the gain of tested antenna, $G_{S}$ is the gain of standard antenna, $P_{T}$ is the power received by tested antenna, $P_{S}$ is the power received by the standard antenna. Equation (8) can be written a as:

$$
G_{T}(d B)=P_{T}(d B m)-P_{S}(d B m)+G_{S}(d B)
$$

If the test antenna is circularly or elliptically polarized, gain measurements using the gain-transfer method can be accomplished by at least two different methods. One way would be to design a standard gain antenna that possesses circular or elliptical polarization. This approach would be attractive in mass productions of power-gain measurements of circularly or elliptically polarized antennas. (ANSI/IEEE Std 149-1979, 1979). The other way would be to use a standard linearly polarized antenna. Thus, the gain of antenna under test have to be measured in two orthogonal orientations. In the measurements. The first method was used using standard known gain helical antenna.

Therefore, the measured gain of the single element using gain transfer method was $6.79 \mathrm{dBi}$, and the result was presented in Figure 8. In $y z$-plane, the main magnitude was $4.9 \mathrm{~dB}$ in a direction of zero degree and beamwidth of 35.90 .

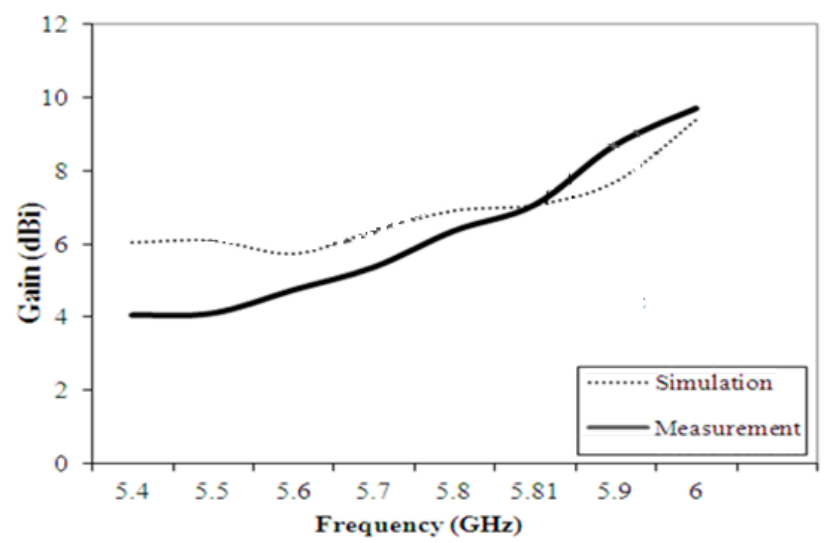

FIGURE 8. Directional characteristics of the proposed antenna.

\section{CONCLUSION}

Experimental design procedures for microstrip-fed triangular microstrip loop resonator antenna have been presented. The proposed antenna was fed by a microstrip feed line using the standing wave ratio over a short ended microstrip feeder. Measurements of the antenna show radiation patterns with moderate gain and acceptable side lobes level of about $-5.43 \mathrm{~dB}$. The proposed antenna demonstrated a significant size reduction capability both in terms of footprint as well as the antenna real estate. With the new feed technique, a size reduction of well over $45 \%$ is achievable when compared it with a conventional rectangular patch antenna operating at $5.8 \mathrm{GHz}$. On a general note, reasonable agreement between simulation and measurement data was obtained. Also, the proposed antenna is easy to fabrication, and exhibits low radiation loss.

REFERENCES

Arulaalan, M. and Nithyanandan, L. 2013. Return loss improvement in an inset fed triangular patch antenna. Communications and Signal Processing (ICCSP), 2013 International Conference on, pp. 864867, 3-5 April 2013.

Bakshi, U. A. and Bakshi, A. V. 2009. Transmission Lines and Waveguides. Pune, Technical Publications.

Carr, J. J. 2001. Practical Antenna Handbook. New York, McGraw-Hill.

Chen, J. and Xue, Q. 2005. Novel microstrip bandpass filter using one equilateral triangular-patch resonator. Microwave Opt. Technol. Lett. 44: 222-223.

Das, A., Puri, M. and Sengar, J. S. 2013. A novel monolithic integrated phased array antenna using 4-bit distributed MEMS phase shifter and triangular patch antenna," Advances in Computing, Communications and Informatics (ICACCI), 2013 International Conference on , 913-918, 22-25 Aug. 2013

Dam, M., Mazumder, S. and Biswas, M. 2013. “Accurate CAD model for computation of input impedance of equilateral triangular patch antenna on suspended and composite substrates," Microwave and Photonics (ICMAP), 2013 International Conference on , 1-4, 13-15 Dec. 2013

Deshmukh, A. A., Jain, A. R. and Ray, K. P. 2013. Analysis of broadband pair of slot cut equilateral triangular microstrip antenna," Advances in Technology and Engineering (ICATE), 2013 International Conference on , 1-6, 23-25 Jan. 2013

Harlan, H., Mumford, R. \& Puttre, M. 2006. Military microwaves 2006 - Current Viewpoints on Air Defense Systems. Military Microwaves Supplement, Microwave Journal: 8-28. 
He, S., Simovski, C. R. and Popov, M. 2000. An explicit and efficient method for obtaining the radiation characteristics of wire antennas in metallic photonic bandgap structures. Microwave and Optical Technology Letters 26: 67-73.

Helszajn, J. and James, D. S. 1978. Planar triangular resonators with magnetic walls. Microwave Theory and Techniques, IEEE Transactions 26(2): 95- 100.

Hong, J. and Lancaster, M. J. 1996. Couplings of microstrip square open-loop resonators for cross-coupled planar microwave filters. Microwave Theory and Techniques, IEEE Transactions 44(11): 2099-2109.

Hong, J. S. and Li, S. 2004. Theory and experiment of dualmode microstrip triangular-patch resonators and filters. IEEE Trans. Microwave Theory Tech. 52: 1237-1243.

Lu, J.-H. 1999. Novel dual-frequency design of single-feed equilateral-triangular microstrip antenna. Microwave Optical Technology Lett. 22(20): 133-136.

Lugo, C. and Papapolymerou , J. 2005. Bandpass filter design using a microstrip triangular loop resonator with dual-mode operation. Microwave and Wireless Components Letters, IEEE. 15(7): 475- 477.

Malek, F. M., Shukor, Md, Abd Aziz, M. Z. A., Nornikman, H. Zulkefli, Mat, M. S. H. M. B., Ahmad, H., Abd Malek, M. F., Othman, M. A. 2013. Equilateral triangular microstrip patch antenna with spur lines embedded, Antennas and Propagation Conference (LAPC), 2013 Loughborough, pp. 303306, 11-12 Nov 2013.

Matsuo, M., Yabuki, H. and Makimoto, M. 2001. Dualmode stepped impedance ring resonator for bandpass filter applications. IEEE Trans. Microwave Theory Tech. 49(7): 1235-1240.

Nasimuddin, K. Esselle, and A. K Verma. 2005. Resonance frequency of an equilateral triangular microstrip antenna. Microwave and Optical Technology Letters 47: 485-489.

Ogasawara, N. and Noguchi, T. 1974. Modal analysis of dielectric resonator of the normal triangular cross section. 1974 Annual National Convention of IEEE, Japan, 1974.

Saputra, W. N., Prasetya, B. and Wahyu, Y. 2013. Design and realization of two array triangle patch of microstrip antenna with gold plat at frequency 2400 $2450 \mathrm{MHz}$ for hexagonal nanosatellite. Information and Communication Technology (ICoICT), 2013 International Conference of , 322-327, 20-22 March 2013
Toutain, Y., Coupez, J.-P. and Person, C. 2001. Microstrip miniaturized loop-filters with high out-of-band rejection for future $3 \mathrm{G}$ mobile terminals. Microwave Symposium Digest, 2001 IEEE MTT-S International 3: 1589-1592 vol. 3, 2001.

Vendelin, G. D., Pavio, A. M., \& Rohde, U. L. 2005. Microwave Circuit Design using Linear and Nonlinear Techniques. New Jersey: Wiley.

Waldschmidt, C., Kuhnert, C., Pauli, M. \& Wiesbeck, W. 2005. Handy MIMO. Communications Engineer 3: $22-25$.

Wang, X., Ji, W. and Li, Y. 2003. Microstrip bandpass filter using one single patch resonator with two transmission zeros. Electron. Lett. 39(17): 1255-1256.

Wansch, R. 2002. Small antennas for wireless microsystems. Active and Passive Electronic Components 25: 71-82.

Zhao, L.-P., Dai, X.-W., Chen, Z.-X. and Liang, C.-H. 2013. Novel Design of Dual -Mode Dual-Band Bandpass Filter with Triangular Resonators. Progress in Electromagnetic Research, PIER 77: 417-424.

Zulkifli, F., Daryanto, Y., Rahardjo E. T. 2013. Slot ring triangular patch antenna with stub for MIMO $2 \times 2$ wireless broadband application. Antennas \& Propagation (ISAP), 2013 Proceedings of the International Symposium on 2: 885-887, 23-25 Oct. 2013.

Seyi Stephen Olokede, Mohd Fadzil Ain, Mohammed Ariff Othman \& Ubaid Ullah

School of Electrical \& Electronic Engineering

Universiti Sains Malaysia

14300 Nibong Tebal,

Penang, Malaysia.

Zainal Araffin Ahmad

School of Material \& Mineral Resources Engineering Universiti Sains Malaysia

14300 Nibong Tebal,

Penang, Malaysia.

${ }^{*}$ Corresponding author; email: solokede@gmail.com

Received Date: $4^{\text {th }}$ Dec 2013

Accepted Date: $9^{\text {th }}$ April 2014 